\title{
Determination of Malondialdehyde (MDA), Superoxide Dismutase (SOD) and Glutathione Peroxidase (GPx) Levels in Kangal Dogs with Maternal Cannibalism
}

\author{
Nazlı Ercan $^{1 *}$, Mustafa Koçkaya ${ }^{2}$ \\ ${ }^{1}$ Department of Biochemistry, Faculty of Veterinary Medicine, Cumhuriyet University, 58140 Sivas, Turkey \\ ${ }^{2}$ Department of Physiology, Faculty of Veterinary Medicine, Cumhuriyet University, 58140, Sivas, Turkey
}

\begin{tabular}{l}
\hline A R T I C L E I N F O \\
Research Article \\
Received 22 August 2017 \\
Accepted 13 October 2017 \\
\hline
\end{tabular}

Keywords:

Antioxidant enzyme

Cannibalism

Oxidative stress

Kangal dog

Malondialdehyde

$\frac{{ }^{*} \text { Corresponding Author: }}{\text { E-mail: nazliercan@yahoo.com }}$

\begin{abstract}
A B S T R A C T
Oxidative stress, which plays an active role in the pathogenesis of various diseases, continues to be relevant in assessing the condition changes such as aggression. Some of Kangal dogs have been found to eat their own puppies during their first 24 hours following birth, as a case called maternal cannibalism. The present study aims to determine the levels of serum malondialdehyde (MDA), which is a product of lipid peroxidation, and serum glutathione peroxidase (GPx) and superoxide dismutase (SOD) enzymes, which are the parameters of antioxidant defense system, and total protein and albumin levels and to show their relationship with cannibalism. The study material consists of blood and blood serum of 30 Kangal dog breed in total, 15 of which have maternal cannibalism and 15 haven't observed maternal cannibalism as a control group. Glutathione peroxidase, superoxide dismutase, malondialdehyde levels were investigated by means of spectrophotometric method in blood serum of these animals. The difference between the mean values of total protein, GPx, SOD, MDA and albumin was statistically significant in the results obtained. These findings conclude that oxidative stress and antioxidative metabolism plays a role in the pathogenesis of cannibalism in dogs.
\end{abstract}

DOI: https://doi.org/10.24925/turjaf.v5i12.1493-1496.1478

\section{Introduction}

In healthy individuals, reactive oxygen derivatives (ROS), which are formed as a result of normal metabolism, are removed by the antioxidant system, the defense mechanism of the body. In the healthy body, the oxygen radicals and the antioxidant defense mechanism work in perfect balance. Oxidative stress is a result of the destruction of this balance on behalf of radicals is called oxidative stress (Karaca and Güder, 2009).

Many studies have used MDA as an indicator of oxidative stress. When free radicals form, they attack polyunsaturated fatty acids as lipid peroxidation from the chemical reaction chain on the cell membrane. When the fatty acids are destroyed, hydrocarbon gases (pentane or ethane) and aldehydes are formed. As part of the metabolic process produce free radicals by cells continuously.

These free radicals are rendered ineffective by antioxidant defence system enzymes which are superoxide dismutase (SOD), glutathione peroxidase (GPx), catalase and nonenzymatic antioxidants (Urso and Clarkson, 2003).
Maternal cannibalism, in which a mother eats her offspring after birth, is seen in various animal species and is considered an abnormal behavior observed only in high stress conditions, usually explained by nutritional deficiencies or environmental stress (Tartabini, 1991; Dellatore et al., 2009; Culot et al., 2011; Tokuyama et al., 2017).

In this study, it is aimed to determine the levels of lipid peroxidation and antioxidant enzymes in the serum of canine dogs and to evaluate their effects on maternal cannibalism.

\section{Materials and Methods}

The material of the study consists of the blood and blood serums of a total of 30 Kangal dogs with the same feeding and shelter conditions in the breeders around Sivas City and its districts. 15 of which had maternal cannibalism in the first 24 hours after a healthy birth in the clinical examination, and 15 haven't observed maternal cannibalism as a control group. 
This study was carried out with the consent No: 31/25.01.2016 of Local Ethics Committee of Animal Experiments, Cumhuriyet University.

Blood for biochemical analysis was taken from each dog by vena cephalica antebrachii to tubes without anticoagulant and then centrifuged at 4,000 rpm for 10 min. The sera were stored at $-20^{\circ} \mathrm{C}$ until conducted spectrophotometrically according to methods.

\section{Analyzing of Serum Biochemical Parameters}

Serum total protein and albumin determinations were performed on an auto analyser (Mindray BS 200) using commercial kits (Mindray).

\section{Analyzing of Lipid Peroxidation (LP) by (MDA)}

Malondialdehyde (MDA) measurement was done described as Janero (1990). The principle of this method is based on the measurement of the absorbance at $535 \mathrm{~nm}$ as spectrophotometrically of the color that MDA forms with thiobarbituric acid (TBA) in acidic media. Standards were prepared using the 1,1,3,3, tetramethoxypropane. The results were calculated through standard graph.

\section{Analyzing of Superoxide Dismutase (SOD)}

The method of determination according to Sun et al. (1988) and the modification described by Durak et al. (1993), the superoxide generated by the xanthine/xanthine oxidase mechanism is based on nitro blue tetrazolium (NBT) reduction. The resulting superoxide radicals $\left(\mathrm{O}_{2}\right)$ reduce the NBT and form a colored formazan. This complex gives maximum absorbance at $560 \mathrm{~nm}$. When SOD is present in the medium, there is no NBT reduction and it does not come to a blue-violet color, and a light color is formed depending on the amount and activity of the enzyme.

\section{Analyzing of Glutathione Peroxidase (GSH-Px)}

Analyzing GPx activity was evaluated according to Paglia and Valentine (1967) and the modification described by Chen et al. (2000). Activity of GSH peroxidase was determined in spectrophotometrically in absorbance at $340 \mathrm{~nm}$. The results reported as kinetically.

\section{Statistical Analysis}

Student's T test was used to analyze statistical significance of differences between the groups, and comparison between the groups was performed with the SPSS package program (SPSS, 2011).

\section{Results}

Serum GPx, SOD and MDA levels of dogs with maternal cannibalism in the control group are shown in Table 1, while serum total protein and albumin levels are shown in Table 2.

As a result of the normality test applied to the obtained results, MDA, GPx, SOD, total protein and albumin parameters showed normal distribution. The difference between the mean values of total protein, GPx, SOD, MDA $(\mathrm{P}<0.01)$ and albumin $(\mathrm{P}<0.05)$ were statistically significant.
Table 1 Serum SOD, GPx and MDA levels between groups $(\mathrm{n}=15$, mean \pm SE)

\begin{tabular}{l|ccc}
\hline \multicolumn{1}{c|}{ Parameters } & MC & Control & P \\
\hline SOD (U/L) & $133.82 \pm 4.23$ & $86.72 \pm 4.60$ & 0.001 \\
GPx (U/ml) & $0.159 \pm 0.01$ & $0.06 \pm 0.01$ & 0.001 \\
MDA (nmol/ml) & $0.16 \pm 0.01$ & $0.63 \pm 0.02$ & 0.001 \\
\hline
\end{tabular}

Table 2 Serum biochemical levels between groups $(n=15$, mean \pm SE)

\begin{tabular}{l|ccc}
\hline \multicolumn{1}{c|}{ Parameters } & MC & Control & $\mathrm{P}$ \\
\hline Total protein $(\mathrm{g} / \mathrm{L})$ & $6.32 \pm 0.10$ & $7.03 \pm 0.16$ & 0.001 \\
Albumin $(\mathrm{g} / \mathrm{L})$ & $2.27 \pm 0.08$ & $2.65 \pm 0.31$ & 0.014 \\
\hline
\end{tabular}

MC: Maternal cannibalism

\section{Discussion and Conclusion}

Malondialdehyde (MDA), a lipid peroxidation product, is known to be an important predictor of oxidative stress. As part of the metabolic process free radicals and reactive oxygen species (ROS) produce by cells (Urso and Clarkson, 2003; Tüközkan et al., 2006). Changes in lipid peroxidation are thought to be indicative of stress, aging, or damage resulting from toxic effects in cells. Free radicals caused by reactivation of fatty acids resulting from tissue damage cause increases in MDA levels. Following this, the antioxidant defense mechanism becomes active (Karapehlivan et al., 2007). These free radicals, antioxidant defense system enzymes are rendered ineffective by catalase, superoxide dismutase, glutathione peroxidase and nonenzymatic antioxidants (Urso and Clarkson, 2003). Several studies have reported that the level of MDA in pregnancy increases due to the oxidative damage of free radicals (Bhale et al., 2013; Swamy et al., 2014; Bassi et al., 2017).

Oxidative stress levels are expected to increase with pregnancy, which is a physiological condition, due to the increased need for higher energy and oxygen requirements of many body functions. Szczubial et al. (2015) investigated the effects of oxidative stress on lipid peroxidation levels in dogs during normal pregnancy. Mean plasma concentrations of pregnant dogs were found to be significantly higher than non-pregnant animals $(\mathrm{P}<0.05)$. They concluded that the concentration of oxidative stress in pregnant dogs may contribute to the risk of pregnancy complications. In this study, malondialdehyde levels were significantly increased in dogs with no cannibalism in comparison with dogs with cannibalism and statistically significant increase was seen, which supported the similar results obtained in a study by Szczubial et al (2015) with levels of oxidative stress increase in normal pregnancy physiology.

However, Nakai et al. (2000) determined the changes in maternal lipid peroxidation level in a study they conducted and measured prenatal and postnatal superoxide dismutase, glutathione peroxidase and catalase levels in uncomplicated pregnancies. Malondialdehyde levels increased during twenty-four hours in postpartum compared to the prenatal period, while superoxide dismutase and catalase levels were found to increase significantly. In this study, the amount of oxidative damage was increased in dogs without cannibalism, 
whereas no increase was observed in antioxidant levels compared to dogs with cannibalism. However, the reduction in MDA levels in dogs with cannibalism is thought to be due to significantly increased SOD and GPX levels. These findings are similar to the postpartum period study by Nakai et al (2000).

Zonturlu et al. (2010) determined serum vitamin E and MDA concentrations in blood samples taken at the beginning of proestrus, oestrus and diestrus to determine in different periods of estrous cycle in female dogs whether there is a relationship between serum vitamin E, malondialdehyde (MDA) concentrations and some reproductive characteristics. They concluded that dogs with a high vitamin E concentration at the beginning of proestrous are at high levels up to the onset of diestrus and that the concentration of vitamin $\mathrm{E}$, which is a strong antioxidant, is high at the onset of proestrus is associated with a lower MDA value at the beginning of estrus. In this study, it is concluded that MDA levels, which are significantly lower in female dogs with maternal cannibalism, are related to high SOD and GPx activities which is similar opinion about antioxidant metabolismoxidant mechanism with Zonturlu et al (2010).

Different outcomes have been reported for oxidative stress and antioxidative defense activities in various diseases in animals. Some studies have suggested that pharmacologically or genetic alterations produce oxidative stress which can cause anxiety-like behavior and that genetic manipulations or antioxidants play a role in therapy (de Oliveira et al., 2004; Hovata et al., 2005; Masood et al., 2008; Salim et al., 2010a; Salim et al., 2010b). Rammal et al. (2010) reported a positive correlation as a statistically significant between oxidative stress and aggressive behavior in male adult rats.

Almeida et al. (2009) investigated the relationship between oxidative stress and liver markers after cadmium exposure in order to evaluate aggressive behavior in the Nile tilapia (Oreochromis niloticus). In cats exposed to cadmium, the decrease and decrease in aggression behaviors were reflected in glutathione peroxidase (GSHPx) levels. However, total superoxide dismutase (SOD) activity increased in the lower animals. In another study, it was found that active behavior in parrots was associated with oxidative damage and that the DNA damage of active budgerigars was greater than that of sedentary birds (Larcombe et al., 2015). Increased SOD levels due to a possible oxidative stress in this study were similar to those of Almeida et al. (2009), but the increase in GPx levels did not overlap with the results of the study.

The reactive oxygen species plays a role in various diseases and aging. But the exact physiological effects of the inducing oxidants are still mostly undefined. Kumsta et al. (2011) investigated the behavioral and physiological relationships of Caenorhabditis elegans with cellular measurements by applying short-time peroxide stress therapy in a study designed to examine animal behavior. As a result, they found that exposure to peroxide stress caused a series of sudden changes such as loss of mobility, a decrease in growth rate, and a decrease in cellular adenosine triphosphate levels, and contributed to physiological and behavioral changes in oxidative stressed animals. However, in C. elegans, they have also emphasized that activation of effective antioxidant systems is important (Kumsta et al., 2011). It is characterized by the decline in MDA levels in dogs with maternal cannibalism. It is thought that the increase in GPx and SOD levels may cause this decrease.

In conclusion, in this study, increased MDA levels and accompanying albumin levels in dogs with no maternal cannibalism within the first 24 hours of postpartum increased in accordance with pregnancy physiology. However, the levels in the antioxidant enzymes were not accompanied by a remarkable increase in the number of dogs with maternal cannibalism. However, the remarkable decrease in MDA and albumin levels as lipid peroxidation products in dogs with maternal cannibalism, which is considered abnormal behavior, is noteworthy and is thought to be related to increased serum antioxidant levels. This reveals that maternal cannibalism in maternal Kangal dogs should be investigated in detail in terms of antioxidative metabolism. Determination of oxidative stress and damage may be a guide.

\section{References}

Almeida JA, Barreto RE, Novelli EL, Castro FJ, Moron SE. 2009. Oxidative stress biomarkers and aggressive behavior in fish exposed to aquatic cadmium contamination. Neotropical ichthyology, 7(1): 103-108.

Bassi R, Kaur M, Sharma, S. 2011. Study of changes in lipid profile, lipid peroxidation and superoxide dismutase during normal pregnancy. Indian Journal of Fundamental and Applied Life Sciences, 1(3): 249-54.

Chen N, Liu Y, Greiner CD, Holtzman JL. 2000. Physiologic concentrations of homocysteine inhibit the human plasma GSH peroxidase that reduces organic hydroperoxides. J Lab Clin Med, 136: 58-65.

Culot L, Lledo-Ferrer Y, Hoelscher O, Lazo FJM, Huynen MC, Heymann, EW. 2011. Reproductive failure, possible maternal infanticide, and cannibalism in wild moustached tamarins, Saguinus mystax. Primates, 52(2): 179-186.

Dellatore DF, Waitt CD, Foitova I. 2009. Two cases of motherinfant cannibalism in orangutans. Primates 50: 277-281.

Durak I, Yurtaslanı Z, Canbolat O, Akyol O. 1993. A methodolgical approach to superoxide dismutase (SOD) activity assay based on inhibition of nitroblue tetrazolium (NBT) reduction. Clin Chim Acta, 214: 103-104.

Hovatta I, Tennant RS, Helton R, Marr RA. 2005. Glyoxalase 1 and glutathione reductase 1 regulate anxiety in mice. Nature, 438 (7068), 662-666.

Janero DR. 1990. Malondialdehyde and thiobarbituric acidreactivity as diagnostic indices of lipid peroxidation and peroxidative tissue injury. Free Radic Biol Med, 9: 515-540.

Karaca Ş, Güder H. 2009. Dermatolojide Antioksidan Sistem. Turk J Dermatol. 3: 32-39.

Kumsta C, Thamsen M, Jakob U. 2011. Effects of oxidative stress on behavior, physiology, and the redox thiol proteome of Caenorhabditis elegans. Antioxidants \& redox signaling, 14(6): 1023-1037.

Larcombe SD, Tregaskes CA, Coffey J, Stevenson AE, Alexander LG, Arnold, KE 2015. Oxidative stress, activity behaviour and body mass in captive parrots. Conservation physiology, 3(1): cov045.

Masood A, Nadeem A, Mustafa SJ, O'Donnell JM. 2008. Reversal of oxidative stress-induced anxiety by inhibition of phosphodiesterase-2 in mice. Journal of Pharmacology and Experimental Therapeutics, 326(2): 369-379.

Nakai A, Oya A, Kobe H, Asakura H, Yokota A, Koshino T, Araki T. 2000. Changes in maternal lipid peroxidation levels and antioxidant enzymatic activities before and after delivery. Journal of Nippon Medical School, 67(6): 434-439. 
de Oliveira MR, Silvestrin RB, e Souza TM, Moreira JCF. 2007. Oxidative stress in the hippocampus, anxiety-like behavior and decreased locomotory and exploratory activity of adult rats: effects of subacute vitamin A supplementation at therapeutic doses. Neurotoxicology, 28(6): 1191-1199.

Paglia DE, Valentine WN. 1967. Studies on the quantitative and qualitative characterization of erythrocyte glutathione peroxidase. J Lab Clin Med, 70: 158-169.

Rammal H, Bouayed J, Soulimani R. 2010. A direct relationship between aggressive behavior in the resident/intruder test and cell oxidative status in adult male mice. Eur J Pharmacol, 627: 173-176.

Salim S, Asghar M, Chugh G, Taneja M, Xia Z, Saha K. 2010a. Oxidative stress: a potential recipe for anxiety, hypertension and insulin resistance. Brain research, 1359: 178-185.

Salim S, Sarraj N, Taneja M, Saha K, Tejada-Simon MV, Chugh G. 2010b. Moderate treadmill exercise prevents oxidative stressinduced anxiety-like behavior in rats. Behavioural brain research, 208(2): 545-552.

SPSS. 2011. Statistical Packages for the Social Sciences, 20 ed. IBM Inc., Chicago.

Sun Y, Oberley LW, Li Y. 1988. Simple for clinical assay of superoxide dismutase. Clin Chem, 34: 497-500.
Szczubiał M, Kankofer M, Dąbrowski R, Bochniarz M, UrbanChmiel R. 2015. Assessment of lipid and protein peroxidation markers in non-pregnant and pregnant female dogs. Polish journal of veterinary sciences, 18(1): 171-179.

Tartabini A. 1991. Mother-infant cannibalism in thick-tailed bushbabies (Galago crassicaudatus umbrosus). Primates 32: 379-383

Tokuyama N, Moore DL, Graham KE, Lokasola A, Furuichi T. 2017. Cases of maternal cannibalism in wild bonobos (Pan paniscus) from two different field sites, Wamba and Kokolopori, Democratic Republic of the Congo. Primates, 58(1): 7-12.

Tüközkan N, Erdamar H, Seven I. 2006. Measurement of total malondialdehyde in plasma and tissues by high-performanced liquid chromatography and thiobarbituric acid assay. Firat Tip Dergisi, 11: 88-92.

Urso ML, Clarkson PM. 2003. Oxidative stress, exercise and antioxidant supplementation. Toxicology. 189: 41-54.

Zonturlu AK, Sönmez M, Türk G, Yüce A. 2010. Dişi köpeklerde östrus siklusunun farklı dönemlerindeki serum ve malondialdehid düxeyleri ile bazı üreme özelliklerinin değerlendirilmesi. FÜ Sağ Bil Vet Derg, 24(3): 115-121. 